\title{
Generation of a DNA-Launched Reporter Replicon Based on Dengue Virus Type 2 as a Multipurpose Platform
}

\author{
Jose A. Usme-Ciro ${ }^{a}$ b Jaime A. Lopera ${ }^{a}$ Diego A. Alvarez ${ }^{a}$ Luis Enjuanes ${ }^{c}$ \\ Fernando Almazán ${ }^{c}$ \\ a Molecular and Translational Medicine Group, Facultad de Medicina, Universidad de Antioquia, Medellin, and \\ ${ }^{b}$ Centro de Investigación en Salud para el Trópico - CIST, Universidad Cooperativa de Colombia, Troncal del

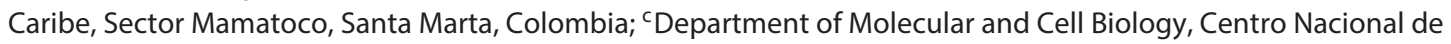 \\ Biotecnología (CNB-CSIC), Campus Universidad Autónoma, Madrid, Spain
}

\section{Keywords}

Dengue virus · Flavivirus · Replicon · Bacterial artificial chromosome $\cdot$ Eukaryotic promoter

\begin{abstract}
Dengue viruses (DENV) have become the most important arthropod-borne viruses, causing dengue and severe dengue fever in at least 50-100 million cases each year, mainly in tropical and subtropical countries. During recent years, important advances in the molecular biology concerning the life cycle of these viruses have allowed the manipulation and generation of recombinant viruses and replicons with multiple applications, mainly in viral biology and the screening of antiviral compounds. In the present study, we describe the construction of an enhanced green fluorescent proteinbearing DENV replicon under the control of the cytomegalovirus immediate early promoter. Following a rational in silico design and cloning by standard molecular biology techniques, a reporter DENV-2 replicon and a replication-deficient mutant were constructed, and characterized by confocal microscopy and real-time RT-PCR. The results showed successful transcription, translation, and autonomous viral RNA replication of the DENV replicon from its DNA clone.
\end{abstract}

\section{KARGER}

(C) 2017 S. Karger AG, Basel

E-Mail karger@karger.com

www.karger.com/int
This novel DENV replicon will allow the study of viral replication and testing of antiviral candidates without the need for in vitro transcription.

(c) 2017 S. Karger AG, Basel

Dengue virus (DENV) constitutes an antigenic complex of 4 serotypes of viruses belonging to the genus Flavivirus within the Flaviviridae family [1], responsible for an estimate of 390 million human infections each year in over 100 tropical and subtropical countries, ranging from asymptomatic to severe dengue fever [2]. They are cytoplasmic viruses with single-stranded positive-sense RNA genomes of around 10.7 kilobases [1]. At the $5^{\prime}$ end they possess a 7-methyl guanosine cap structure, which allows binding of the eukaryotic translation initiation factor $4 \mathrm{E}$ (eIF4E) to start the assembly of the preinitiation complex and the $80 \mathrm{~S}$ ribosomal complex [3]. The first $96 \mathrm{nt}$ of the viral genome spanning the $5^{\prime}$ untranslated region ( $5^{\prime} \mathrm{UTR}$ ) correspond to a highly structured RNA region with at

Jose A. Usme-Ciro

Facultad de Medicina, Universidad Cooperativa de Colombia

Troncal del Caribe, Sector Mamatoco

Santa Marta 470003 (Colombia)

E-Mail jose.usmec@campusucc.edu.co

Fernando Almazán

Campus Universidad Autónoma

Darwin 3

ES-28049 Madrid (Spain)

E-Mail falmazan@cnb.csic.es 


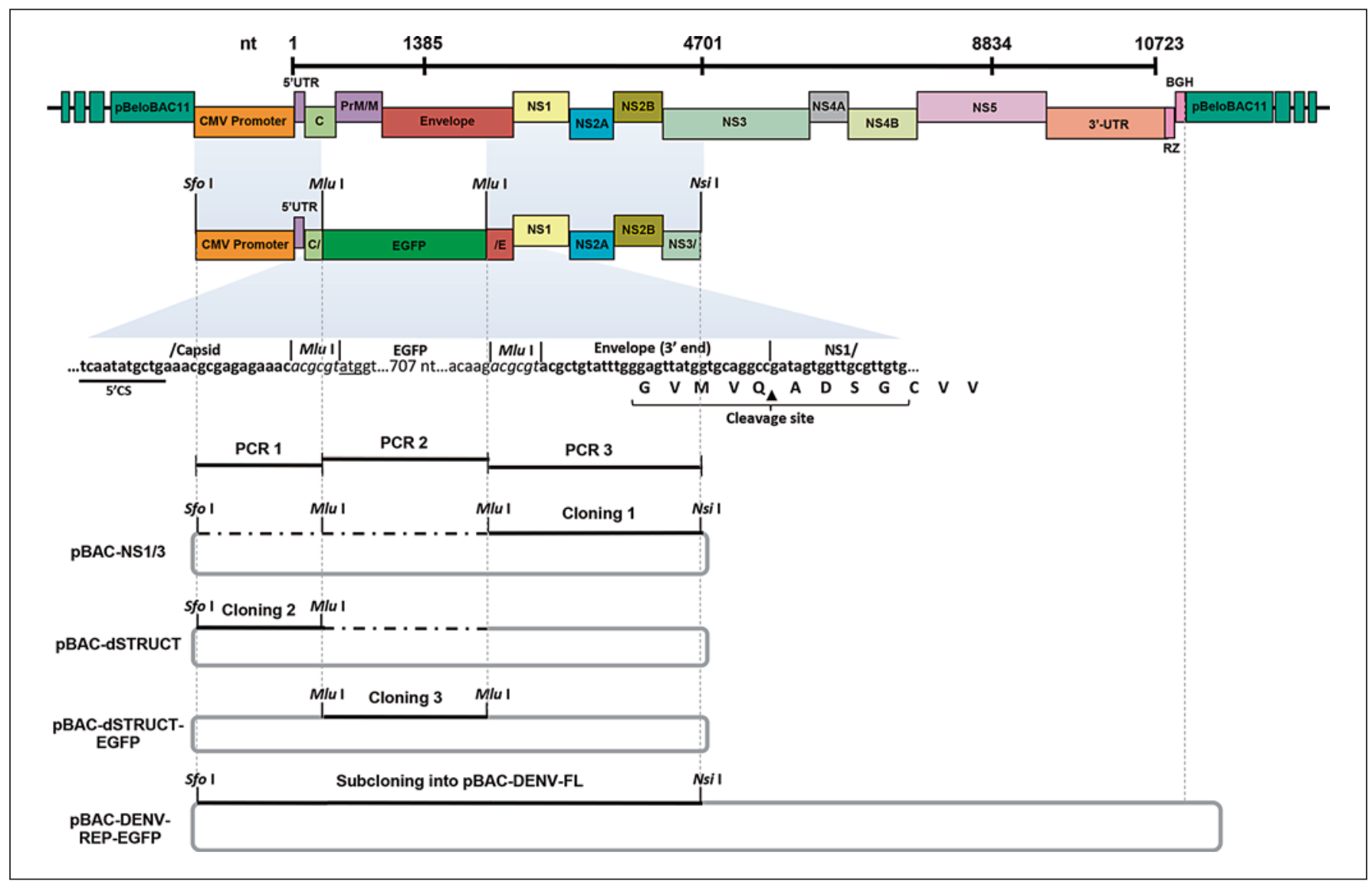

Fig. 1. Assembly of a DNA-launched DENV replicon expressing EGFP. The replicon was generated by means of PCR amplification, cloning, and subcloning into pBAC-DENV-FL, where the structural genes were replaced by the reporter EGFP gene. The viral genes ( $C, \operatorname{PrM} / M$, Envelope, NS1, NS2A, NS2B, NS3, NS4A, NS4B, and NS5), the $5^{\prime}$ and $3^{\prime}$ UTRs, the CMV promoter, the hepatitis delta virus ribozyme (RZ), and the bovine growth hormone (BGH) polyadenylation and termination sequences are illustrated by boxes. Relevant restriction sites used for the assembly of the replicon, the $5^{\prime} \mathrm{CS}$ sequence, and the cleavage site at the E-NS1 junction are also indicated.

NS4A, NS4B, and NS5) proteins. Although the function of some nonstructural proteins is yet to be deciphered, it appears that all of them play important roles in virus replication and morphogenesis [1]. The $3^{\prime} \mathrm{UTR}$ of DENV of around $450 \mathrm{nt}$ contains a highly variable region, a semivariable region, a highly structured region containing several stem-loop structures (pseudoknot 2, PK2, PK1, 3' stem-loop), and elements responsible for viral RNA circularization ( $\left.3^{\prime} \mathrm{CS}, 3^{\prime} \mathrm{DAR}, 3^{\prime} \mathrm{UAR}\right)$, which have been differentially involved in replication in insect and mammalian cells $[3,6]$.

An increasing number of DENV replicons containing the minimal cis-acting elements and genes encoding for the replicase complex have been reported in the last decade. The vast majority of these replicons are driven by the T7 and SP6 prokaryotic promoters, which require in 
Table 1. Oligonucleotides used for the generation of the DENV replicon

\begin{tabular}{|c|c|c|c|c|}
\hline Name & Orientation & $\begin{array}{l}\text { Amplicon } \\
\text { size, bp }\end{array}$ & $\begin{array}{l}\text { Restriction } \\
\text { endonucleases }\end{array}$ & Sequence $\left(5^{\prime} \rightarrow 3^{\prime}\right)$ \\
\hline NS1-F & $\mathrm{F}$ & 2,363 & SfoI, $M l u \mathrm{I}$ & aatgatggcgccgcgcacgcgtacgctgtatttgggagttat \\
\hline DENV1385-4701R & $\mathrm{R}$ & 2,363 & SphI, NsiI (partial) & gaagagcatgctggttcaatcctctttcctttat \\
\hline CMV5 & $\mathrm{F}$ & 782 & SfoI & aatgatggcgccttgacattgattattgactagttattaatag \\
\hline $\mathrm{C} 21-\mathrm{R}$ & $\mathrm{R}$ & 782 & SphI & gaagaacgcgtgtttctctcgcgtttcagc \\
\hline PEGFP-F & $\mathrm{F}$ & 736 & MluI & gcgcacgcgtatggtgagcaagggcgaggag \\
\hline PEGFP-R & $\mathrm{R}$ & 736 & MluI & gcgcacgcgtcttgtacagctcgtccat \\
\hline GVD-F & $\mathrm{F}$ & 1,573 & & tcagtggagTtgattgtgttgtg \\
\hline GVD-R & $\mathrm{R}$ & 744 & & cacaacacaatcaActccact \\
\hline DEN2R5 & $\mathrm{F}$ & 744 & PmlI & gaagtcggcacgtgaggctgttgaagatagt \\
\hline BAC-R & $\mathrm{R}$ & 1,573 & & tgattacgccaagctatttagg \\
\hline NS3 F F & $\mathrm{F}$ & 458 & & gcacaaagaagagggagaatagg \\
\hline NS3_R & $\mathrm{R}$ & 458 & & tagcgccagtgggtcagagtag \\
\hline NS5_F & $\mathrm{F}$ & 88 & & tcacaccatttccatgagttaatca \\
\hline NS5_R & $\mathrm{R}$ & 88 & & cgggctctaccaatcagttca \\
\hline NS5_DENV & $\mathrm{F}$ & - & & FAM-ccgcgtacttgtagttccatgcagaaacc \\
\hline
\end{tabular}

Underlined sequences correspond to recognition sites for restriction endonucleases used in the cloning strategy. Bold sequences correspond to oligonucleotide regions that hybridize with the DENV genome. Italicized sequences correspond to the complementary regions between forward and reverse oligonucleotides. F, forward; R, reverse; FAM, 6-carboxyfluorescein.

vitro transcription and subsequent transfection of the synthesized RNAs [7]. A reduced number of the available replicons are driven by the eukaryotic cytomegalovirus promoter $(\mathrm{CMV})$, which allows direct transcription in plasmid-transfected eukaryotic cells [8-13]. All of these replicons have enormous potential for answering fundamental questions about the viral biology, expression of heterologous genes, and have become powerful platforms for high-throughput screening of antiviral compounds and siRNAs. Here, we describe the construction and characterization of a CMV immediate early promoterdriven DENV-2 replicon generated from a highly attenuated substrain of the DENV-2 New Guinea C (NGC) strain.

For the derivation of this DNA-launched DENV replicon (pBAC-DENV-REP-EGFP) we used the previously constructed DENV-2 infectious clone (pBAC-DENVFL) containing the cDNA of the NGC prototype strain (DENV-2 NGC M2) [14], which showed a highly attenuated phenotype in Vero cells [15]. The pBAC-DENV-FL, which contains the bacterial artificial chromosome (BAC) backbone for increased stability of cloned fragments, was propagated in Escherichia coli DH10B, as previously described [16]. All subsequently generated BAC clones were propagated in the same way and the plasmid DNA purified using the Qiagen Large-Construct kit (Qiagen $\mathrm{GmbH}$, Hilden, Germany).

The strategy for the assembly of the enhanced green fluorescent protein (EGFP)-containing DENV replicon under the control of the CMV promoter (pBAC-DENVREP-EGFP) initially consisted of obtaining 3 PCR fragments (PCR 1, PCR 2, and PCR 3) comprising the CMV5'UTR-C (60 nt), EGFP, and NS1-NS2-NS3 (up to 4,701 nt) that were sequentially cloned into pBeloBAC11 to generate the pBAC-dSTRUCT-EGFP plasmid, in which the region encoding the structural proteins $C$, $p r M / M$, and $E$ was exchanged with the reporter EGFP gene (Fig. 1; Table 1; see online suppl. Resource 1; for all online suppl. material, see www.karger.com/doi/10.1159/000476066). To generate the DNA-launched DENV replicon, the $S f o I-$ $N s i$ fragment from the pBAC-DENV-FL infectious clone [14] was exchanged by the corresponding fragment from the plasmid pBAC-dSTRUCT-EGFP (Fig. 1). The first $60 \mathrm{nt}$ of the capsid-coding region were preserved because of the presence of the $\mathrm{CHP}$ and $5^{\prime} \mathrm{CS}$ elements that are essential for virus replication. In addition, the region encoding for the cleavage site at the E-NS1 junction was also preserved to allow the separation of the NS1 from the reporter EGFP protein. The genetic integrity of the cloned DNAs was verified throughout the assembly process by sequencing using specific oligonucleotides (see online suppl. Resources 2-4).

To further study the functionality of the DENV replicon, the active site (GDD motif) of the RNA-dependent RNA polymerase, RdRP, was mutated to GVD by means of overlapping PCR using the mutagenic oligonucleotides GVD_F and GVD_R to disable its RNA polymerase activity [5], generating the pBAC-DENV-REP-GVD con- 


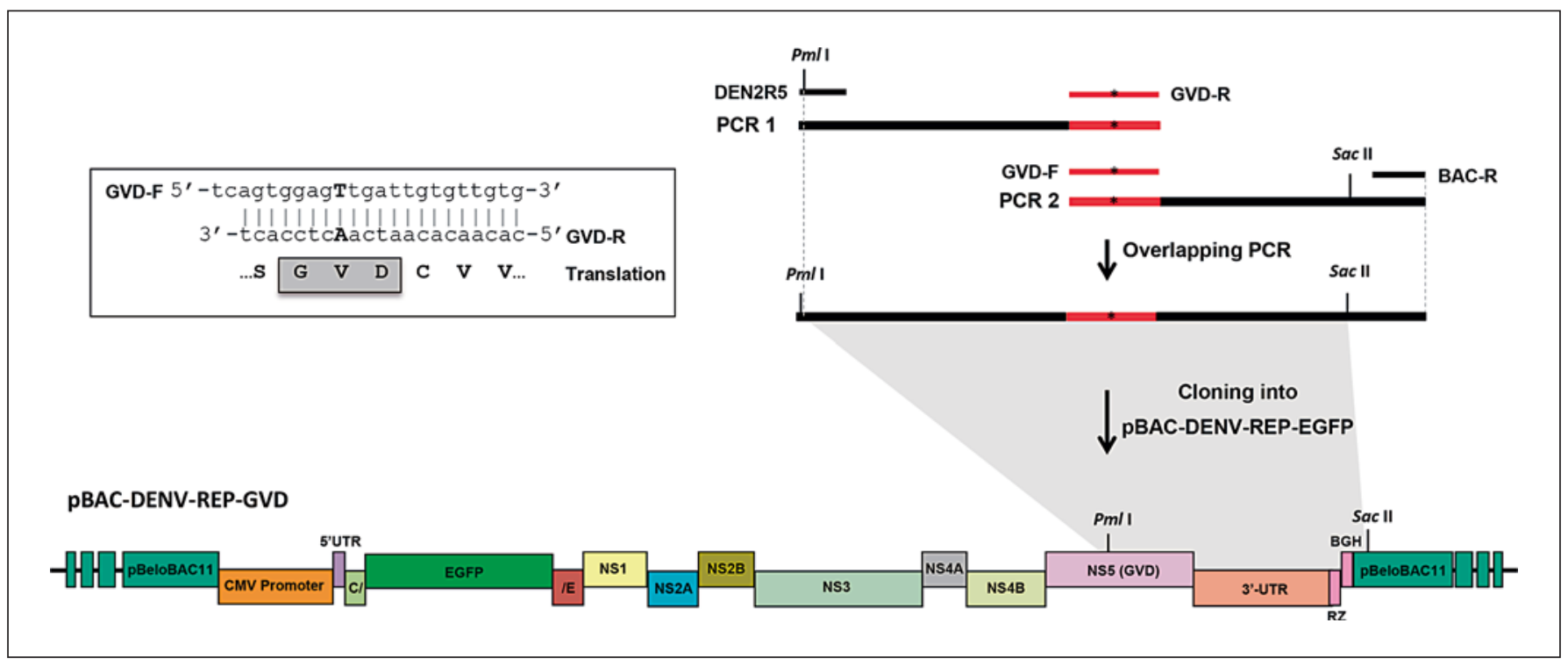

Fig. 2. Generation of the mutant pBAC-DENV-REP-GVD. The strategy and the sequence of the mutagenic oligonucleotides, GVD-F, and GVD-R used for the generation of the GVD mutant of the DENV replicon are shown. The acronyms for the viral genes and regulatory elements are as defined in the legend to Figure 1. struct, which could transcribe and translate from the CMV promoter, but not autonomously replicate (Fig. 2; Table 1; online suppl. Resource 1).

The first question that emerges when using a eukaryotic promoter to artificially transcribe sequences not belonging to the eukaryotic system is the possibility of having functional donor-acceptor sites for splicing that could truncate important regions of the transcribed sequence during mRNA maturation. The ability of the DNAlaunched DENV replicon to be transcribed from the CMV eukaryotic promoter and subsequently translated was therefore analyzed. To this end, Vero cells were grown on coverslips to $90 \%$ confluence in 24 -well plates and subsequently transfected with $2 \mu \mathrm{g}$ of pBAC-DENVREP-EGFP and Lipofectamine ${ }^{\mathrm{TM}} 2000$ (Life Technologies Corp., Carlsbad, CA, USA) according to manufacturer's instructions. Cells were fixed and the expression of the reporter EGFP and the viral NS3 protein at $48 \mathrm{~h}$ posttransfection (hpt) was evaluated by fluorescence microscopy analysis (see online suppl. Resource 1). In contrast to nontransfected cells, EGFP and NS3 expression were detected in cells transfected with the DENV replicon (Fig. 3a), demonstrating that the replicon was successfully transcribed and translated. These findings are in agreement with the absence of donor and acceptor sites being used for splicing in the DENV genome that could lead to the elimination of crucial genome regions after transcription from the CMV promoter and eukaryotic mRNA maturation. Furthermore, the presence of NS3 indicates that the replicon open reading frame was preserved after elimination of the structural genes and insertion of the reporter gene. Even with a potential high score splicing donor site at position 3,395 (corresponding to the NS1 gene) as previously described [14], the ability of the DENV replicon to translate the EGFP and NS3 proteins, located upstream and downstream of this predicted position, respectively, allowed this possibility to be discarded. These results were also supported by previous findings of the successful rescue of an infectious clone of DENV-2 under the control of the CMV promoter [14].

In spite of the evidence that the DNA-launched DENV replicon can efficiently transcribe and translate, it was necessary to demonstrate its ability to autonomously replicate the DENV replicon genome. Therefore, total RNA from cellular lysates of transfected cells at 24 or $48 \mathrm{hpt}$ was extracted with the RNeasy minikit (Qiagen, Chatsworth, CA, USA) following the manufacturer's instructions. The RNA extracts were further treated with RQ1 RNase-free DNase I (Promega Corp., Fitchburg, WI, USA) and used for conventional and real-time 2-step reverse transcription-polymerase chain reaction (RT-PCR). In conventional RT-PCR, the presence of negative- or positivesense viral RNA strands was evaluated using the oligonucleotides NS3_F or NS3_R (Table 1) at the RT step, 


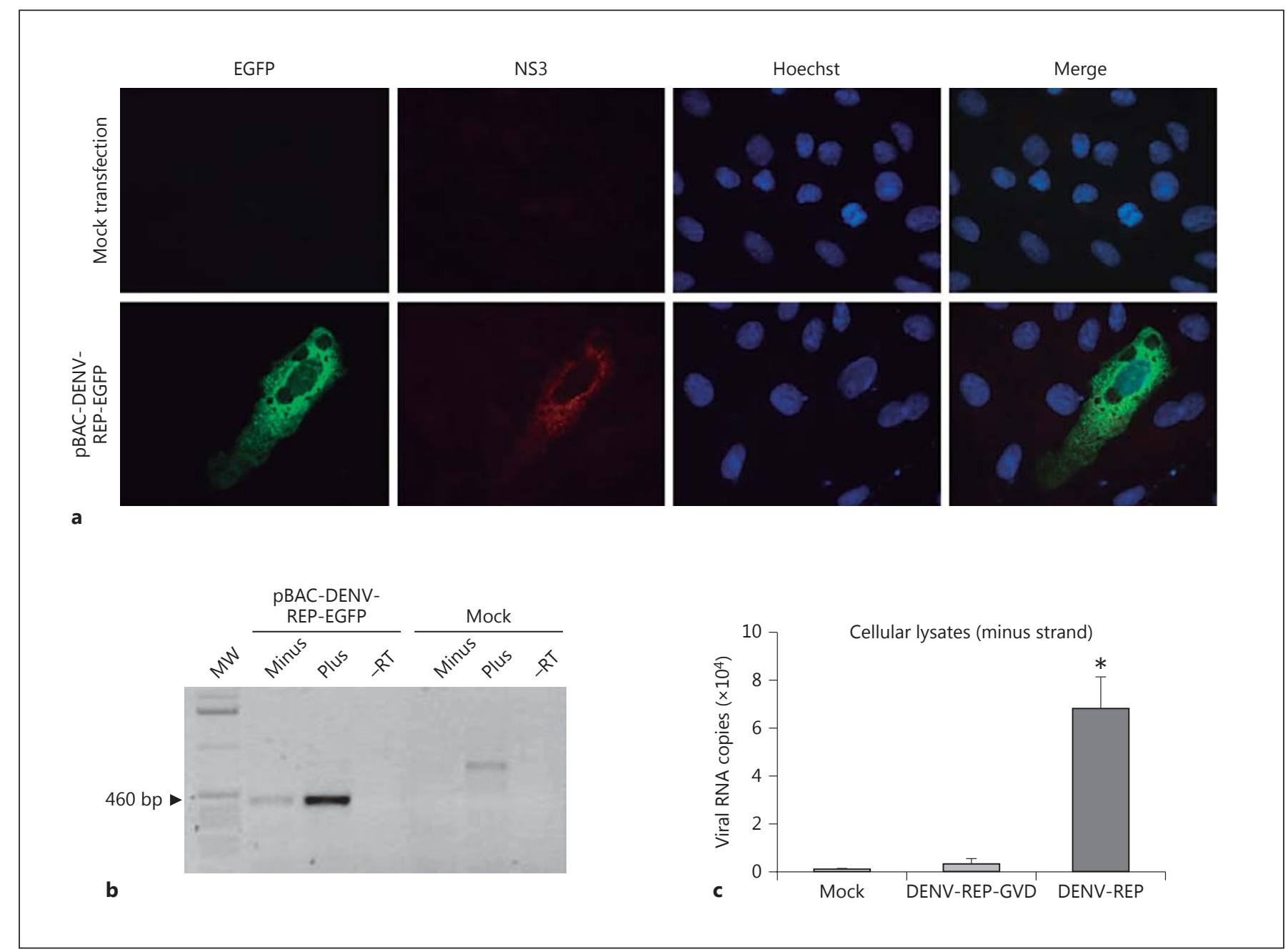

Fig. 3. Functional analysis of the DNA-launched DENV replicon. a Functional analysis of the DENV replicon by fluorescence confocal microscopy. Vero cells were mock transfected or transfected with pBAC-DENV-REP-EGFP and the expression of EGFP and NS3 analyzed at $48 \mathrm{hpt}$. NS3 was detected using the monoclonal antibody E1D8 and a secondary antibody conjugated to AlexaFluor $^{\circledR} 594$ dye. Nuclei were stained with Hoechst. b Functional analysis of the DENV replicon by conventional RT-PCR. Vero cells were mock transfected or transfected with pBAC-DENVREP-EGFP. Total RNA was isolated at $48 \mathrm{hpt}$, treated with DNase I, and the presence of negative ("Minus") and positive ("Plus") strands of the DENV replicon were analyzed by conventional RT-

respectively, followed by PCR with both oligonucleotides. In real-time RT-PCR (qRT-PCR), the presence of negative strands was evaluated using the oligonucleotide NS5_F (Table 1) at the RT step, followed by qPCR with the oligonucleotides NS5_F, NS5_R, and the TaqMan ${ }^{\circledR}$ MGB $^{\mathrm{TM}}$ probe NS5_DENV (Table 1), using the RotorGene ${ }^{\circledR}$ Q Real-Time PCR system (Qiagen) as previously

Generation of a DNA-Launched Dengue

Virus Type 2 Reporter Replicon
PCR. Oligonucleotides NS3_F and NS3_R were used during the cDNA synthesis step for detection of the minus and plus strand, respectively. $-\mathrm{RT}$, negative control of reverse transcription; MW, molecular weight markers. c Functional analysis of DENV replicon by qRT-PCR. The amount of negative-sense replicon RNA (minus strand) was determined by qRT-PCR in RNA samples isolated at $24 \mathrm{hpt}$ from Vero cells mock transfected or transfected with the wild-type replicon (pBAC-DENV-REP-EGFP) or the mutant replicon (pBAC-DENV-REP-GVD) using the oligonucleotides NS5_F and NS5_R, and the NS5_DENV probe. Values are expressed as viral RNA copies per reaction. Error bars represent the SEM. ${ }^{*} p<0.05$.

described [14]. For relative quantification of viral RNA levels in cellular lysates, the endogenous $18 \mathrm{~S}$ ribosomal RNA (Applied Biosystems, Foster City, CA, USA) was used as a reference gene to correct the level of starting genetic material. The conventional RT-PCR results demonstrated the presence of negative strands of viral RNA in cellular lysates of transfected cells resulting from autono-

Intervirology 2016;59:275-282 279 
Fig. 4. Cytopathicity analysis of the DENV replicon in Vero cells by fluorescence confocal microscopy. Vero cells were mock transfected or transfected with either the wild-type (pBAC-DENV-REP-EGFP) or the nonreplicative (pBAC-DENV-REPGVD) replicons and analyzed at 12,24 , and $36 \mathrm{hpt}$. Images are representative of the total experiment.



mous replication, as well as a major proportion of the positive-sense viral RNA strands (Fig. 3b). In addition, significant levels of negative-sense viral RNA genomes were detected by qRT-PCR in the DENV replicon-transfected cells, in contrast with the DENV-REP-GVD-transfected cells, in which the levels were not significantly different from the mock-transfected cells (Fig. 3c). While positive-sense viral RNA genomes can be produced by transcription from the CMV promoter or active viral replication, negative-sense viral RNA genomes can be exclusively produced by the RdRP activity during viral replication. These results indicate that the DENV replicon can autonomously replicate the viral genome and that the replication-deficient mutant could be used as a useful negative control for future replication experiments, as expected.

In order to analyze the cytopathicity of the replicon in cell cultures, a time-course experiment was performed. To this end, Vero cells were transfected with either the DENV replicon or the replication-deficient mutant, and the expression of EGFP was analyzed at 12, 24, and $36 \mathrm{hpt}$ by fluorescent confocal microscopy. The expression of the EGFP was observed at very early time points (12 hpt), as expected from the CMV-driven transcription, and reached a maximum at $24 \mathrm{hpt}$ without morphological alteration of the transfected cells (Fig. 4). After $24 \mathrm{hpt}$, the transfected cells dramatically changed their morphology, becoming retracted and loosing attachment to the culture plate (data not shown), suggesting that the DENV was cytopathic in Vero cells. While the role of the reporter EGFP in inducing morphological changes cannot be ruled out, similar results were obtained with both constructs (replicon and replication-deficient mutant), suggesting that the cytopathicity could be induced by the expression of at least one of the viral nonstructural proteins and not necessarily the result of overloading the cellular machinery during active 
replication of the viral genome. The mechanism of morphological alterations in transfected cells could not be elucidated in this study; however, cell death and loss of replicon-positive cells after $50 \mathrm{hpt}$ in LLC-MK $\mathrm{MK}_{2}$ cells was previously reported [17], and the role of structural and some nonstructural DENV proteins in inducing apoptosis by extrinsic or intrinsic pathways has been demonstrated [18-21] and could be an explanation. The cytopathic effect has been widely correlated to acute infections with RNA viruses, and was the first limitation in the development of alphavirus replicons as viral vectors for gene therapy [22]. A very interesting approach to overcome this problem consisted in inserting a selectable marker into a SINV replicon genome and selecting clones with normal or nearly normal cell growth and virus replication properties which showed an adaptive mutation responsible for the noncytopathic phenotype $[23,24]$. Future studies with the present DENV replicon should include the identification of the determinants of cytopathicity and the selection of noncytopathic replicons.

Keeping in mind the absence of licensed antiviral drugs and potential limitations of currently approved vaccine against dengue $[25,26]$, DENV replicons have become important tools to confront dengue by facilitating the study of virus and host factors involved in viral replication and the establishment of high-throughput screening platforms for antiviral drug discovery by inserting reporter and selection markers, and the generation of stable replicon-expressing cell lines $[7,8,13,27$, 28]. In spite of the extensive work with replicons of closely related flaviviruses (KUN strain of West Nile virus, Japanese encephalitis virus, Tick-borne encephalitis virus, and Yellow fever virus) [29-34], and their use as promissory viral vectors for heterologous gene expression [3537 , to the best of our knowledge only 1 study has pro- posed the use of a DENV replicon as a viral vector, specifically for HIV-1 protein expression with dual vaccination purposes, against dengue and HIV [17]. The DENV reporter replicon described here will allow the study of fundamental questions of DENV replication, and will become the backbone for a promising viral vector for RNA interference therapy [38].

In conclusion, we have described the construction of a DENV replicon under control of the CMV promoter, which was evaluated and showed to replicate and translate properly. This construct is a tool for deciphering fundamental processes of viral-host interaction during viral RNA synthesis and has the potential to be a backbone for the development of an antiviral screening platform. Further experiments may help us to provide additional evidence of the flavivirus packaging requirements, and to propose this system as the first step in the development of a novel DENV-based viral vector for the delivery of small regulatory RNAs.

\section{Acknowledgements}

This study was financially supported through funding from the Departamento Administrativo de Ciencia, Tecnología e Innovación - Colciencias (Colombia) grant 111545921525, and the Ministry of Economy of Spain (MINECO; BIO2013-42869-R) and the Fogarty International Center and NIA NIH Institute under Award No. RO1-AG029802-01. The content is solely the responsibility of the authors and does not necessarily represent the official views of the National Institutes of Health. J.A.U.-C. was recipient of a National Doctoral Fellowship from Colciencias.

\section{Disclosure Statement}

The authors declare that they have no conflicts of interest.

\section{References}

1 Lindenbach BD, Murray CL, Thiel H-J, Rice CM: Flaviviridae; in Knipe DM, Howley PM (eds): Fields Virology. Philadelphia, Lippincott, Williams \& Wilkins, 2013, pp 712-746.

2 Bhatt S, Gething PW, Brady OJ, Messina JP, Farlow AW, Moyes CL, Drake JM, Brownstein JS, Hoen AG, Sankoh O, Myers MF, George DB, Jaenisch T, Wint GR, Simmons CP, Scott TW, Farrar JJ, Hay SI: The global distribution and burden of dengue. Nature 2013;496:504-507.

3 Paranjape SM, Harris E: Control of dengue virus translation and replication. Curr Top Microbiol Immunol 2010;338:15-34.

Generation of a DNA-Launched Dengue

Virus Type 2 Reporter Replicon
4 Friebe P, Pena J, Pohl MO, Harris E: Composition of the sequence downstream of the dengue virus $5^{\prime}$ cyclization sequence (dCS) affects viral RNA replication. Virology 2012;422:346-356.

5 Clyde K, Barrera J, Harris E: The capsid-coding region hairpin element (cHP) is a critical determinant of dengue virus and West Nile virus RNA synthesis. Virology 2008;379:314-323.

6 Alvarez DE, De Lella Ezcurra AL, Fucito S, Gamarnik AV: Role of RNA structures present at the $3^{\prime} U T R$ of dengue virus on translation, RNA synthesis, and viral replication. Virology 2005;339:200-212.
7 Kato F, Hishiki T: Dengue virus reporter replicon is a valuable tool for antiviral drug discovery and analysis of virus replication mechanisms. Viruses 2016;8:E122.

8 Ansarah-Sobrinho C, Nelson S, Jost CA, Whitehead SS, Pierson TC: Temperature-dependent production of pseudoinfectious dengue reporter virus particles by complementation. Virology 2008;381:67-74.

9 Leardkamolkarn V, Sirigulpanit W, Chotiwan N, Kumkate S, Huang CY: Development of dengue type-2 virus replicons expressing GFP reporter gene in study of viral RNA replication. Virus Res 2012;163:552-562. 
10 Leardkamolkarn V, Sirigulpanit W: Establishment of a stable cell line coexpressing dengue virus- 2 and green fluorescent protein for screening of antiviral compounds. J Biomol Screen 2012;17:283-292.

11 Lee TC, Lin YL, Liao JT, Su CM, Lin CC, Lin WP, Liao CL: Utilizing liver-specific microRNA-122 to modulate replication of dengue virus replicon. Biochem Biophys Res Commun 2010;396:596-601.

12 Pang X, Zhang M, Dayton AI: Development of dengue virus type 2 replicons capable of prolonged expression in host cells. BMC Microbiol 2001;1:18.

13 Yang CC, Tsai MH, Hu HS, Pu SY, Wu RH, Wu SH, Lin HM, Song JS, Chao YS, Yueh A: Characterization of an efficient dengue virus replicon for development of assays of discovery of small molecules against dengue virus. Antiviral Res 2013;98:228-241.

14 Usme-Ciro JA, Lopera JA, Enjuanes L, Almazan F, Gallego-Gomez JC: Development of a novel DNA-launched dengue virus type 2 infectious clone assembled in a bacterial artificial chromosome. Virus Res 2014;180:12-22.

15 Friebe P, Harris E: Interplay of RNA elements in the dengue virus $5^{\prime}$ and $3^{\prime}$ ends required for viral RNA replication. J Virol 2010;84:61036118.

16 Almazán F, Galán C, Enjuanes L: Engineering infectious cDNAs of coronavirus as bacterial artificial chromosomes. Methods Mol Biol 2008;454:275-291.

17 Pang X, Zhang M, Dayton AI: Development of dengue virus replicons expressing HIV-1 gp120 and other heterologous genes: a potential future tool for dual vaccination against dengue virus and HIV. BMC Microbiol 2001; $1: 28$.

18 Morchang A, Yasamut U, Netsawang J, Noisakran S, Wongwiwat W, Songprakhon P, Srisawat C, Puttikhunt C, Kasinrerk W, Malasit P, Yenchitsomanus PT, Limjindaporn T: Cell death gene expression profile: role of RIPK2 in dengue virus-mediated apoptosis. Virus Res 2011;156:25-34.

19 Duarte dos Santos CN, Frenkiel MP, Courageot MP, Rocha CF, Vazeille-Falcoz MC, Wien MW, Rey FA, Deubel V, Despres P: Determinants in the envelope $\mathrm{E}$ protein and viral RNA helicase NS3 that influence the induction of apoptosis in response to infection with dengue type 1 virus. Virology 2000;274:292308.
20 Brabant M, Baux L, Casimir R, Briand JP, Chaloin O, Porceddu M, Buron N, Chauvier $\mathrm{D}$, Lassalle $\mathrm{M}$, Lecoeur $\mathrm{H}$, Langonne A, Dupont S, Deas O, Brenner C, Rebouillat D, Muller S, Borgne-Sanchez A, Jacotot E: A flavivirus protein $\mathrm{M}$-derived peptide directly permeabilizes mitochondrial membranes, triggers cell death and reduces human tumor growth in nude mice. Apoptosis 2009;14: 1190-1203.

21 Lin CF, Lei HY, Shiau AL, Liu HS, Yeh TM, Chen SH, Liu CC, Chiu SC, Lin YS: Endothelial cell apoptosis induced by antibodies against dengue virus nonstructural protein 1 via production of nitric oxide. J Immunol 2002;169:657-664.

22 Frolov I, Hoffman TA, Pragai BM, Dryga SA, Huang HV, Schlesinger S, Rice CM: Alphavirus-based expression vectors: strategies and applications. Proc Natl Acad Sci USA 1996; 93:11371-11377.

23 Dryga SA, Dryga OA, Schlesinger S: Identification of mutations in a Sindbis virus variant able to establish persistent infection in BHK cells: the importance of a mutation in the nsP2 gene. Virology 1997;228:74-83.

24 Agapov EV, Frolov I, Lindenbach BD, Pragai BM, Schlesinger S, Rice CM: Noncytopathic Sindbis virus RNA vectors for heterologous gene expression. Proc Natl Acad Sci USA 1998;95:12989-12994.

25 Usme-Ciro JA, Méndez JA, Laiton KD, Páez $\mathrm{A}$ : The relevance of dengue virus genotypes surveillance at country level before vaccine approval. Hum Vaccin Immunother 2014;10: 2674-2678.

26 Halstead SB: Critique of World Health Organization recommendation of a dengue vaccine. J Infect Dis 2016;214:1793-1795.

27 Ng CY, Gu F, Phong WY, Chen YL, Lim SP, Davidson A, Vasudevan SG: Construction and characterization of a stable subgenomic dengue virus type 2 replicon system for antiviral compound and siRNA testing. Antiviral Res 2007;76:222-231.

28 Qing M, Liu W, Yuan Z, Gu F, Shi PY: A highthroughput assay using dengue-1 virus-like particles for drug discovery. Antiviral Res 2010;86:163-171

29 Yun SI, Choi YJ, Yu XF, Song JY, Shin YH, Ju YR, Kim SY, Lee YM: Engineering the Japanese encephalitis virus RNA genome for the expression of foreign genes of various sizes: implications for packaging capacity and RNA replication efficiency. J Neurovirol 2007;13: 522-535.
30 Pijlman GP, Suhrbier A, Khromykh AA: Kunjin virus replicons: an RNA-based, noncytopathic viral vector system for protein production, vaccine and gene therapy applications. Expert Opin Biol Ther 2006;6:135-145.

31 Gehrke R, Heinz FX, Davis NL, Mandl CW: Heterologous gene expression by infectious and replicon vectors derived from tick-borne encephalitis virus and direct comparison of this flavivirus system with an alphavirus replicon. J Gen Virol 2005;86:1045-1053.

32 Varnavski AN, Young PR, Khromykh AA: Stable high-level expression of heterologous genes in vitro and in vivo by noncytopathic DNA-based Kunjin virus replicon vectors. J Virol 2000;74:4394-4403.

33 Varnavski AN, Khromykh AA: Noncytopathic flavivirus replicon RNA-based system for expression and delivery of heterologous genes. Virology 1999;255:366-375.

34 Bonaldo MC, Caufour PS, Freire MS, Galler $\mathrm{R}$ : The yellow fever $17 \mathrm{D}$ vaccine virus as a vector for the expression of foreign proteins: development of new live flavivirus vaccines. Mem Inst Oswaldo Cruz 2000;95(suppl 1): 215-223.

35 Huang YT, Liao JT, Yen LC, Chang YK, Lin YL, Liao CL: Japanese encephalitis virus replicon-based vaccine expressing enterovirus-71 epitope confers dual protection from lethal challenges. J Biomed Sci 2015;22:74.

36 Pyankov OV, Bodnev SA, Pyankova OG, Solodkyi VV, Pyankov SA, Setoh YX, Volchkova VA, Suhrbier A, Volchkov VV, Agafonov AA, Khromykh AA: A Kunjin replicon virus-like particle vaccine provides protection against Ebola virus infection in nonhuman primates. J Infect Dis 2015;212(suppl2):S368S371.

37 Yoshii K, Hayasaka D, Goto A, Kawakami K, Kariwa H, Takashima I: Packaging the replicon RNA of the Far-Eastern subtype of tickborne encephalitis virus into single-round infectious particles: development of a heterologous gene delivery system. Vaccine 2005;23: 3946-3956.

38 Usme-Ciro JA, Campillo-Pedroza N, Almazán F, Gallego-Gomez JC: Cytoplasmic RNA viruses as potential vehicles for the delivery of therapeutic small RNAs. Virol J 2013;10:185. 